\title{
Coconut water and BAP successfully replaced zeatin in olive (Olea europaea L.) micropropagation
}

\author{
A. Peixe* , A. Raposo, R. Lourenço, H. Cardoso, E. Macedo \\ Inst. Ciências Agr. Mediterrânicas, Universidade de Évora, Lab. Melhoramento e Biotec. Vegetal, Ap. 94, 7002-554 Évora, Portugal
}

Received 3 February 2006; received in revised form 19 December 2006; accepted 12 January 2007

\begin{abstract}
The data presented report on trials conducted during 24 months using the Portuguese olive cultivar 'Galega vulgar'. The effectiveness of coconut water, BAP, or kinetin, as possible zeatin substitutes in olive micropropagation protocols, was investigated. In all stages of the micropropagation process, the mineral and vitamin formulation of olive medium $(\mathrm{OM})$ was used. Regarding culture establishment the best results were achieved when $50 \mathrm{ml}^{-1}$ coconut water and $2.22 \mu \mathrm{M}$ BAP were used as medium supplements. For the in vitro multiplication stage, the highest proliferation rates with an average of 3.4 new explants on each 30 days were achieved maintaining the coconut water concentration at $50 \mathrm{ml}^{-1}$ and increasing BAP up to $8.87 \mu \mathrm{M}$. The effects of IBA and activated charcoal on the in vitro root induction were also studied. Rooting rates of over $85 \%$ were obtained by basal immersion of the explants in IBA solution at $3 \mathrm{~g}^{-1}$ for $10 \mathrm{~s}$, followed by inoculation in the OM culture medium, added with $2 \mathrm{~g} \mathrm{l}^{-1}$ of activated charcoal and without growth regulators. All in vitro rooted plants were transferred into Jiffy-Pots filled with vermiculite-perlite $3: 1(\mathrm{v} / \mathrm{v})$ substrate. Those were subsequently wetted with the OM mineral solution, placed into polystyrene plates each one with 100 Jiffy-Pots capacity, which were transferred to traditional rooting mist benches, on a water-cooling equipped greenhouse. Such a simple acclimatization procedure allowed for $95 \%$ of plants survival.
\end{abstract}

(C) 2007 Elsevier B.V. All rights reserved.

Keywords: Coconut water; In vitro culture; Micropropagation; Olea europaea; Olive; Zeatin

\section{Introduction}

Olive (Olea europaea L.) is one of the most important fruit species of the Mediterranean region being usually propagated by leafy cuttings under mist. The olive cultivar 'Galega vulgar', known to be very difficult to multiply by this procedure, is of particular importance for Portugal, as it stands for almost $70 \%$ of all the Portuguese olive orchards.

Although the propagation of several fruit species difficult to multiply by traditional methods has been made possible by micropropagation, regarding the olive micropropagation, there is not yet enough knowledge for its use in a mass scale nursery production (Zuccherelli and Zuccherelli, 2002).

\footnotetext{
Abbreviations: IBA, indol-3-butyric acid; Benomyl, methyl 1-[(butylamino)carbonyl]- $H$-benzimidazol-2-yl carbamate; LSDleast significant difference; MIRugini initial medium; MSMurashige and Skoog medium; NAA $\alpha$-naphthalene acetic acid; OMRugini olive medium

* Corresponding author. Tel.: +351 919718680; fax: +351 266760821.

E-mail address: apeixe@uevora.pt (A. Peixe).
}

The first known scientific reports on in vitro olive propagation are from the mid 1970s, where researchers tried to optimize the mineral media formulations for all of the culture stages, in order to establish a micropropagation protocol that would suit all cultivars. From this point-of-view the OM medium (Rugini, 1984), the MSI, original MS medium (Murashige and Skoog, 1962), modified by Fiorino and Leva (1986) and the MSM, also original MS medium modified by Leva et al. (1992), are considered up-to-now as the most suitable ones for olive micropropagation, but they also proved not to be effective for all cultivars (Grigoriadou et al., 2002).

Besides the mineral formulation, growth regulators are also one of the most important components of the in vitro culture media. Since the pioneering work of Rugini (1984) that zeatin has been widely accepted as the only cytokinin capable of inducing satisfactory growth in olive cultured explants. It has been generally used at rates rising from 4.56 to $45.62 \mu \mathrm{M}$. However, due to its high cost, there is also a generalized opinion that an alternative replacement should be achieved for use in commercial micropropagation protocols (Mencuccini et al., 1997; Briccoli et al., 2002). One alternative to zeatin was 
recently reported by García-Férriz et al. (2002) that replaced it by thidiazuron and BAP. Nevertheless, thidiazuron is still a very expensive chemical compound and economical benefits of zeatin replacement were not yet relevant.

Another important component of all culture media is the energy source, with sucrose being widely used for such purpose. In the multiplication media for olive micropropagation Leva et al. $(1992,1994)$ brought a significant contribution on this subject by replacing sucrose with mannitol. They observed that the increased culture media prices due to mannitol utilization were highly exceeded by the higher multiplication rates and explant growth capacity. Similar observations of increased shoot length and breaking of apical dominance by the use of mannitol on their micropropagation trials with the 'Manzanillo' cultivar were reported by García et al. (2002).

Concerning in vitro rooting, success rates ranging from 25 to $85 \%$ were reported by Rugini (1984), Fiorino and Leva (1986) and Rama and Pontikis (1991) depending on the cultivar tested and on the time of the year when the experiments were carried out. For this culture stage, most researchers directly supplement the culture medium with IBA (indol-3-butyric acid) or NAA ( $\alpha$-naphthalene acetic acid), at rates rising from 1 to $4 \mathrm{mg} \mathrm{l}^{-1}$.

Besides growth regulators, medium illumination is also of relevant importance for the in vitro rooting of olive explants. Significant increases on the rooting rates were achieved by Rugini et al. (1993) by darkening the basal explants after painting in black the outside of the vessels and by placing black sterile polycarbonate granules on the surface of the solidified medium. Looking into replacing Rugini's interesting but cumbersome technique with a simpler and more economic alternative method, Mencuccini (2003) reported rooting rates between 86 and $100 \%$ on its trials with three Italian olive cultivars using the Brilliant Black commercial dye from Sigma ${ }^{\circledR}$ for medium darkening. Still on the subject, Canas et al. (1992) reported that medium darkening it is not of such importance for the adventitious root induction stage but it seams crucial for its further development. This opinion it is not corroborated by Mencuccini (2003), which reported that in vitro olive explants carry over the in vivo seasonal rooting ability of the olive cultivars and the medium darkening process is the only known way to cancel this effect.

In spite of the extensive studies carried out in the last years aiming to improve the culture conditions for some olive cultivars, olive micropropagation success rates are still in general limited. The shoot proliferation rate is generally low and cultivar dependent (Dimassi-Theriou, 1994; Bartolini et al., 1990), the formation of adventitious roots in many micropropagated olive cultivars is still difficult, and the percentage of post-transplanting losses remains high (Briccoli-Bati et al., 1999; Rugini et al., 1999).

The aim of the present study was to report on the development of an efficient micropropagation protocol for an economically important and difficult to root cultivar like it is the 'Galega vulgar'.

\section{Materials and methods}

\subsection{Plant material}

Single node segments each with two opposite buds (Fig. 1) were prepared at the region between the second and fifth nodes from vigorous growing shoots. The shoots were collected in June 2003 from 8-year-old trees, growing in the 'Galega vulgar' mother field of the olive nursery company Plansel S.A. The trees were grown on an alluvial soil with homogeneous chemical and morphological characteristics. Trees were very close to each other $(1 \mathrm{~m} \times 1.25 \mathrm{~m})$ and were systematically submitted to severe pruning. From the 17 'Galega vulgar' clones planted, only one was used for these trials and shoots were randomly collected from each one of the ten trees of the clone.

\subsection{Explant sterilization}

The single node explants were surface sterilized in a three step procedure: washing in tap water for $3 \mathrm{~h}$; immersion in $1 \%$ (w/v) Benomyl solution for $50 \mathrm{~min}$, followed by a threetimes wash in bi-distillate water; immersion in $0.2 \%(\mathrm{w} / \mathrm{v})$ $\mathrm{HgCl}_{2}$ with three drops of Tween 20 on $500 \mathrm{ml}$ water for $10 \mathrm{~min}$, followed by a three-times wash in sterile water. During the immersion periods, both in Benomyl and $\mathrm{HgCl}_{2}$, the explants were continuously shaken on an electric rotary shaker.

\subsection{Culture establishment}

After surface sterilization, the explants were inoculated in $\varnothing 9 \mathrm{~cm}$ Petri dishes containing $15 \mathrm{ml}$ of the MI basal culture medium and vitamin complex, as proposed by Rugini (1984). The growth regulators BAP, kinetin or zeatin were tested alone, or mixed with $50 \mathrm{ml}^{-1}$ coconut water, at 2.22 , 2.32 and $2.28 \mu \mathrm{M}$, respectively. All media were supplemented with $7 \mathrm{~g}^{-1}$ commercial agar-agar and $30 \mathrm{gl}^{-1}$ sucrose.

Cultures were kept for 30 days in a growth chamber with $24{ }^{\circ} \mathrm{C} / 21{ }^{\circ} \mathrm{C}\left( \pm 1{ }^{\circ} \mathrm{C}\right)$ day/night temperature and $15 \mathrm{~h}$ light period, under cool white fluorescent light $\left(36 \mu \mathrm{mol} \mathrm{m}^{-2} \mathrm{~s}^{-1}\right)$.

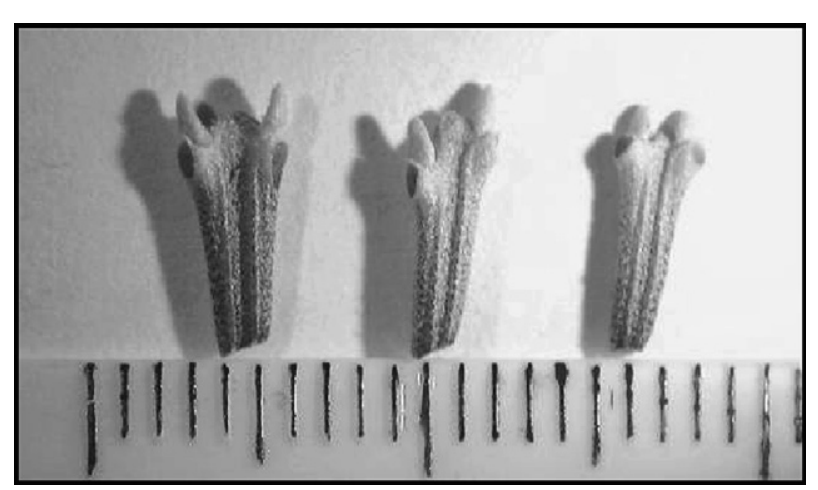

Fig. 1. Uninodal cuttings with 5-7 mm and two axillary buds, were used to initiate the in vitro propagation process. 


\subsection{In vitro multiplication-elongation}

All sprouted explants were transferred to $500 \mathrm{ml}$ glass flasks containing $75 \mathrm{ml}$ of OM basal culture medium and vitamin complex, as proposed by Rugini (1984). The growth regulators, BAP and Zeatin, alone, or mixed with $50 \mathrm{ml} \mathrm{l}^{-1}$ coconut water, were tested at this stage, at 8.87 and $9.12 \mu \mathrm{M}$, respectively. All media were supplemented with $7 \mathrm{~g} \mathrm{l}^{-1}$ commercial agar-agar and $30 \mathrm{~g} \mathrm{l}^{-1}$ D-mannitol.

The explants were kept in culture for 30 days and transferred afterwards to a fresh medium with the same composition for 30 more days.

Growth chamber conditions were maintained as previously described for culture establishment.

\subsection{In vitro rooting and acclimatization}

After 60 days on the multiplication-elongation media the explants were sectioned. The apical parts of the new shoots (apical node with two internodes) were transferred to the rooting media, and the lower parts were fragmented into singlenode cuttings and transferred into the previous multiplication media to restart the process.

The OM basal medium was kept over the rooting stage but Dmannitol was once again replaced by $30 \mathrm{mg} \mathrm{l}^{-1}$ sucrose.

Root induction was performed either by direct inoculation of the explants into the OM basal medium, supplemented with $4.9 \mu \mathrm{M}$ IBA, or by immersion of the explant bases, for $10 \mathrm{~s}$, into a $14,700 \mu \mathrm{M}$ sterile IBA solution, followed by inoculation into the basal medium without growth regulators (procedure from now onwards named pulse technique). All rooting media formulations where tested with or without $2 \mathrm{~g} \mathrm{l}^{-1}$ activated charcoal.

All culture media $\mathrm{pH}$ was adjusted to 5.8 prior to autoclave (20 min at $121{ }^{\circ} \mathrm{C}$ ). Whenever used, coconut water, zeatin and the vitamins complex, were added to the culture media by sterilization using a $0.2 \mu \mathrm{m}$ mesh syringe filter.

Once in vitro rooted, the young plants were rinsed with tap water to remove adhering medium and individually transferred to Jiffy-Pots filled with a vermiculite-perlite 3:1 (v/v) mixture that was subsequently wetted with the OM mineral solution. Polystyrene plates each one with 100 Jiffy-Pots, were than transferred to traditional rooting mist benches, on a watercooling and mist-bench equipped greenhouse, for plant acclimatization.

\subsection{Experimental design}

The experiments were conducted under a complete randomized block design and data behaviour was evaluated by ANOVA analysis. Differences within and between treatments were estimated by mean separation analysis, using the least significant difference (LSD) test, with significance being recorded at $p \leq 0.05$.

At culture establishment, 200 uniform explants were inoculated on each treatment, using 20 Petri dishes, each one with 10 explants. Random groups of 5 Petri dishes were taken as a sample unit for statistical analysis.
Each shoot proliferation experiment lasted in culture for 2 months with a subculture to fresh medium after 30 days. Twelve shoot proliferation experiments, six each year, were developed during the 2-year period of the trials. One hundred uniform explants were inoculated for each treatment on five culture flasks, and, each flask, with 20 explants, was considered as a sample unit for statistical analysis.

At the end of each experiment, the number of new shoots and the number of nodes per shoot was determined. Proliferation rate was evaluated by counting the number of nodes of the shoots produced, considering that every node could be used as a new explant for further subcultures, and it is presented on a 30 days base.

Rooting experiments lasted for 30 days and were performed for three times on each year. At the end of each experiment, the number of rooted shoots was evaluated and rooting capacity expressed as percentage.

The number of successfully acclimatized plants was recorded 1 month after transplanting into the water-cooling and mist-bench equipped greenhouse and expressed as survival percent.

\section{Results}

The performance of the culture media formulations was evaluated at the culture-establishment stage by estimation of the shoot-sprouting percentage. The best results were achieved with the media formulations MI5 and MI1, where the basal medium was supplemented with $50 \mathrm{ml} \mathrm{l}^{-1}$ coconut water plus $2.22 \mu \mathrm{M}$ BAP and $2.28 \mu \mathrm{M}$ zeatin, respectively (Fig. 2). The average sprouting rate was close to $95 \%$ on either treatment showing no statistical significant difference between them. Significantly lower sprouting rates were observed for the two other media formulations tested, MI3 and MI4, with the poorest results being obtained with the MI4 formulation, where kinetin was used at $2.32 \mu \mathrm{M}$. After 30 days in culture, the sprouted explants were transferred into the multiplication media enabling successful elongation of the newly formed microshoots.

Collected data from the multiplication-elongation trials was evaluated by ANOVA analysis (Table 1). It is possible to

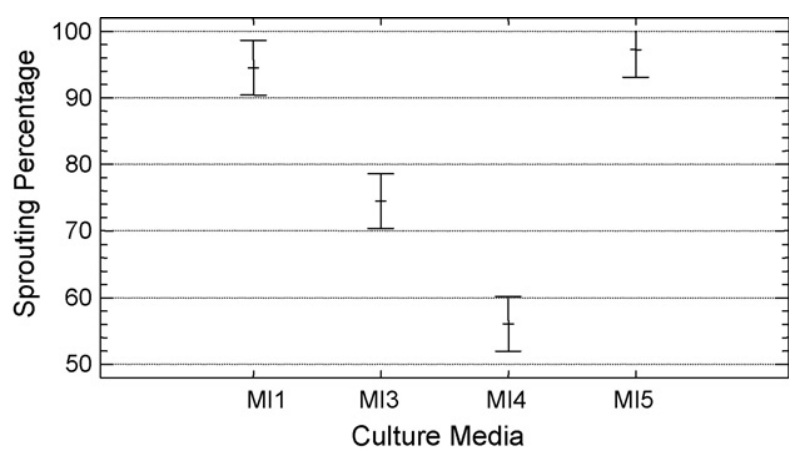

Fig. 2. Spouting percentages for the different media formulations used at the culture installation stage. The MI basal media (Rugini, 1984) was used in all formulations (LSD, 95\%). Legend-MI1: $2.28 \mu \mathrm{M}$ zeatin; MI3: $2.22 \mu \mathrm{M}$ BAP; MI4: $2.32 \mu \mathrm{M}$ kinetin; MI5: $50 \mathrm{ml}^{-1}$ coconut water $+2.22 \mu \mathrm{M}$ BAP. 
Table 1

Analysis of variance for the multiplication rates on a 30 days base

\begin{tabular}{llrlrl}
\hline Source of variation & $\begin{array}{l}\text { Sum of } \\
\text { squares }\end{array}$ & d.f. & $\begin{array}{l}\text { Mean } \\
\text { square }\end{array}$ & $F$-ratio & $\begin{array}{l}\text { Significant } \\
\text { level }\end{array}$ \\
\hline Main effects & & & & & \\
$\quad$ A: time & 0.10613 & 1 & 0.106129 & 0.176 & 0.6817 \\
$\quad$ B: culture medium & 114.87528 & 4 & 28.718819 & 47.517 & $\mathbf{0 . 0 0 0 1}$ \\
$\quad$ C: subculture & 9.79667 & 11 & 0.890607 & 1.474 & 0.1761 \\
Interactions & & & & & \\
$\quad$ A $\times$ B & 1.109990 & 4 & 0.2774974 & 0.459 & 0.7652 \\
$\quad$ A $\times$ C & 9.855180 & 11 & 0.8959255 & 1.482 & 0.1726 \\
$\quad$ B $\times$ C & 38.871103 & 44 & 0.8834342 & 1.462 & 0.1060 \\
Residual & 26.593322 & 44 & 0.6043937 & & \\
Total (corrected) & 201.20768 & 119 & & & \\
\hline
\end{tabular}

0 missing values have been excluded. Type III sums of squares. All $F$-ratios are based on the residual mean square error.

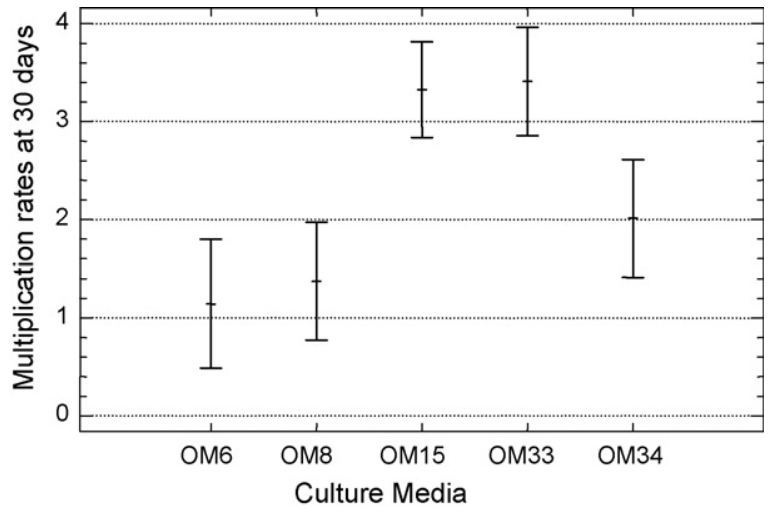

Fig. 3. Multiplication rates at 30 days for different formulations based on the OM basal medium (LSD, 95\%). Legend-OM6: control; OM8: $8.87 \mu \mathrm{M}$ BAP; OM15: $9.12 \mu \mathrm{M}$ zeatin; OM33: $8.87 \mu \mathrm{M}$ BAP $+50 \mathrm{ml} \mathrm{l}^{-1}$ coconut water; OM34: $50 \mathrm{ml}^{-1}$ coconut water.

observe that significant differences on the multiplication rates after 30 days were only found within the culture media. Homogeneous behaviour was observed for the 12 subcultures carried-out during the 2-year experimental period.

Fig. 3 shows the analysis of means separation for the five culture media tested in these trials. No significant differences
Table 2

Analysis of variance for the rooting percentage

\begin{tabular}{llrlrl}
\hline Source of variation & $\begin{array}{l}\text { Sum of } \\
\text { squares }\end{array}$ & d.f. & $\begin{array}{l}\text { Mean } \\
\text { square }\end{array}$ & $F$-ratio & $\begin{array}{l}\text { Significant } \\
\text { level }\end{array}$ \\
\hline Main effects & & & & & \\
$\quad$ A: time & 28.957 & 1 & 28.957 & 0.350 & 0.5689 \\
$\quad$ B: root induction & 46313.489 & 3 & 15437.830 & 186.799 & $\mathbf{0 . 0 0 0 1}$ \\
$\quad$ C: subculture & 627.351 & 5 & 125.470 & 1.518 & 0.2428 \\
Interactions & & & & & \\
$\quad$ A $\times$ B & 84.4972 & 3 & 28.16572 & 0.341 & 0.7962 \\
A $\times$ C & 683.6173 & 5 & 136.72345 & 1.654 & 0.2062 \\
B $\times$ C & 1671.9002 & 15 & 111.46001 & 1.349 & 0.2848 \\
Residual & 1239.6638 & 15 & 82.644251 & & \\
Total (corrected) & 52813.147 & 47 & & & \\
\hline
\end{tabular}

0 missing values have been excluded. Type III sums of squares. All $F$-ratios are based on the residual mean square error.

were observed between the multiplication rates of the control (OM6 formulation) and the media formulations OM8 with BAP $8.87 \mu \mathrm{M}$, or OM34 with coconut water $50 \mathrm{mg}^{-1}$. Otherwise, significantly higher multiplication rates were observed with zeatin at $9.12 \mu \mathrm{M}$ (OM15 formulation), or with BAP at $8.87 \mu \mathrm{M}$ together with $50 \mathrm{mg} \mathrm{l}^{-1}$ coconut water (OM33 formulation). These two media formulations, with no significant differences between them, showed significantly higher multiplication rates than the control, or media containing either BAP or coconut water, whenever those compounds were tested alone.

The images sequence presented in Fig. 4 denote that the cultivar tested showed a very good adaptation to the best in vitro culture conditions used throughout the trials. At the culture establishment stage, both axillary buds had usually sprouted and no hiperhidricity or strong calluses formation was observed in the initial explants (Fig. 4A). After transfer into the multiplication-elongation medium, sprout growth was not inhibited (Fig. 4B) and the explants presented, after 60 days in culture, between 6 and 8 visible internodes (Fig. 4C). Explant transfer into the rooting media was successfully accomplished. Fig. 4D shows in detail which part of the explants where transferred to the rooting media formulations (Fig. 4D_1) and which where maintained at the multiplication stage (Fig. 4D_2).
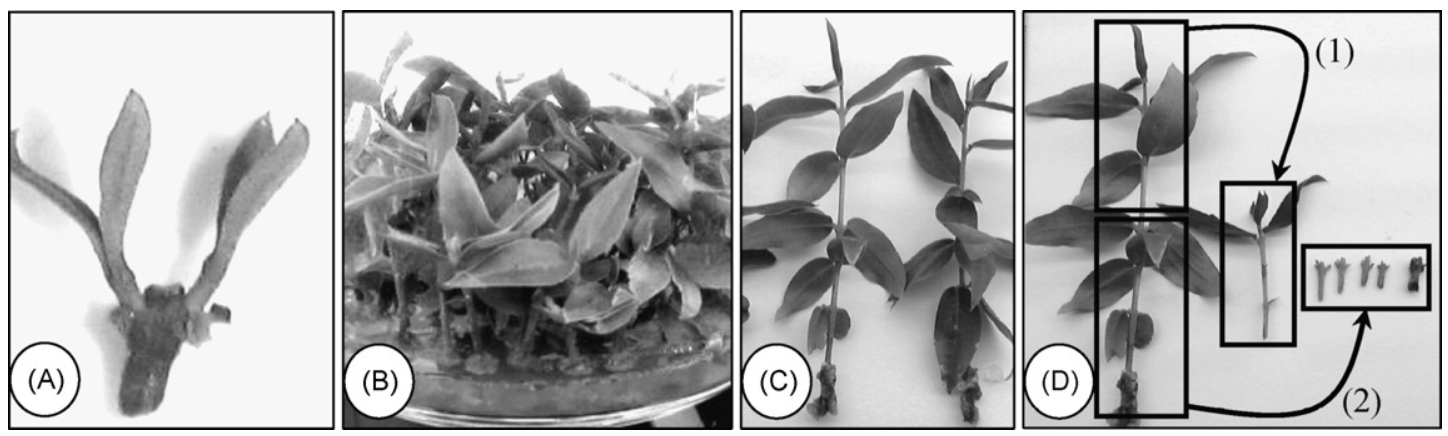

Fig. 4. (A) The two axillary buds spouted in most of the explants after 30 days in induction medium. (B) Development of the explants after 30 days in multiplication media. (C) After 60 days in multiplication media the explants reached seven to eight nodes and are ready to be fragmented. (D) The upper part of the explants is transferred to the rooting medium (1); the lower part of the explants is fragmented into new uninodal cuttings, to restart the multiplication stage (2). 


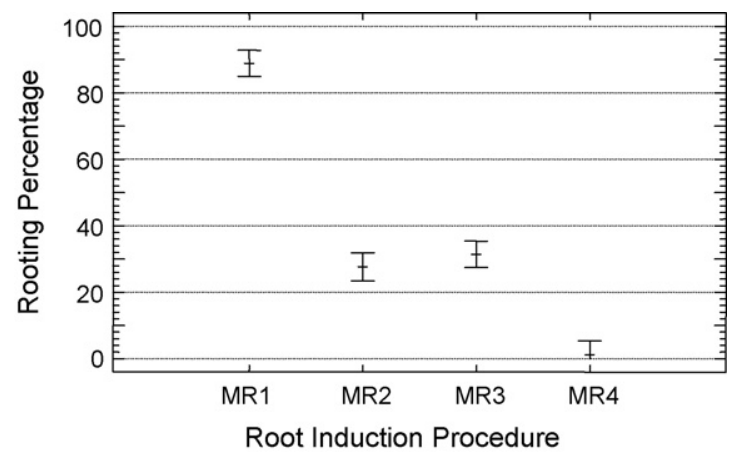

Fig. 5. Rooting rates attained for all the in vitro adventitious root induction procedures (LSD, 95\%). Legend-MR1: IBA $(14,700 \mu \mathrm{M})$ by pulse technique, in medium with $2 \mathrm{~g} \mathrm{l}^{-1}$ activated charcoal; MR2: IBA $(14,700 \mu \mathrm{M})$ by pulse technique, in medium without activated charcoal; MR3: IBA $(4.9 \mu \mathrm{M})$ added to culture medium with $2 \mathrm{~g}^{-1}$ activated charcoal; MR4: IBA $(4.9 \mu \mathrm{M})$ added to culture medium without activated charcoal.

The results from the rooting experiments are presented in Table 2. It can be seen that rooting percentage was affected neither by time nor by subculture. Significant differences on this variable were only found within the rooting induction procedure. Observing the LSD analysis of means, presented in Fig. 5, it is possible to see that the MR1 root induction procedure, where the OM basal medium was supplemented with $2 \mathrm{~g}^{-1}$ activated charcoal, associated with the pulse technique, showed the highest rooting rates ( $88 \%$ on average). The presence of activated charcoal induced significantly higher rooting rates for both the pulse technique and the direct supplementation of auxin to the media. The auxin supplementation of the root induction media always presented the lowest rooting rates.

Fig. 6 shows plants on rooting and acclimatization stages, where quantity and quality of the newly formed roots can be observed. As a result of the very high rooting percentage, the bottom of the culture flasks were full of roots (Fig. 6A). At least four to five well-developed roots were obtained on each explant (Fig. 6B) and the good quality of the newly formed root system was probably the main reason for the high survival rates achieved on the plant-acclimatization stage (Fig. 6C), reaching $95 \%$. No signals of apical bud necrosis were observed during any of the micropropagation stages and growing of the apical meristems was maintained even during the rooting stage of in vitro culture.

\section{Discussion}

As no other viable alternatives were offered so far, zeatin remains in use in recent research work on olive micropropagation (Sghir et al., 2005), despite its high price, which is an effective limitation to the commercial use of developed protocols. Efforts to replace zeatin on the in vitro culture protocols were tried out by several researchers (DimassiTheriou, 1994; Mencuccini et al., 1997; Briccoli et al., 2002; García-Férriz et al., 2002). The available information indicates that zeatin replacement by single synthetic cytokinins, such as BAP or kinetin were not very successful as they did not prove to allow good proliferation rates and usually they induced explant hiperhidricity. One exception was probably with the cultivar 'Kalamon', were the effectiveness of BA for shoot proliferation was documented by Dimassi (1999).

In the present trials with the cultivar 'Galega vulgar', zeatin was successfully replaced by coconut water and BAP. Coconut water is known as a natural substance with high levels of zeatin in its composition, and found in the last years an increased importance in micropropagation protocols of economically important species, such as passion-fruit (Hall et al., 2000), coffee (Ismail et al., 2003) or orchids (Santos-Hernandez et al., 2005). At the best of our knowledge, this is the first time that its use is being mentioned in olive micropropagation protocols.

As it happens with other reports on zeatin replacement, where the association of different cytokinins is presented as the best way to improve the multiplication rates (Grigoriadou et al., 2002; García-Férriz et al., 2002), also in this trials the single effect of coconut water was not sufficient to promote satisfactory multiplication. The best results were obtained with a blend of coconut water and BAP, allowing an average multiplication rate of 3.4 new explants on each 30 days.

Considering that the propose of this research was to achieve a full suitable protocol for micropropagation of the olive cultivar 'Galega vulgar' and not only the objective of zeatin replacement at the multiplication culture stage, rooting trials
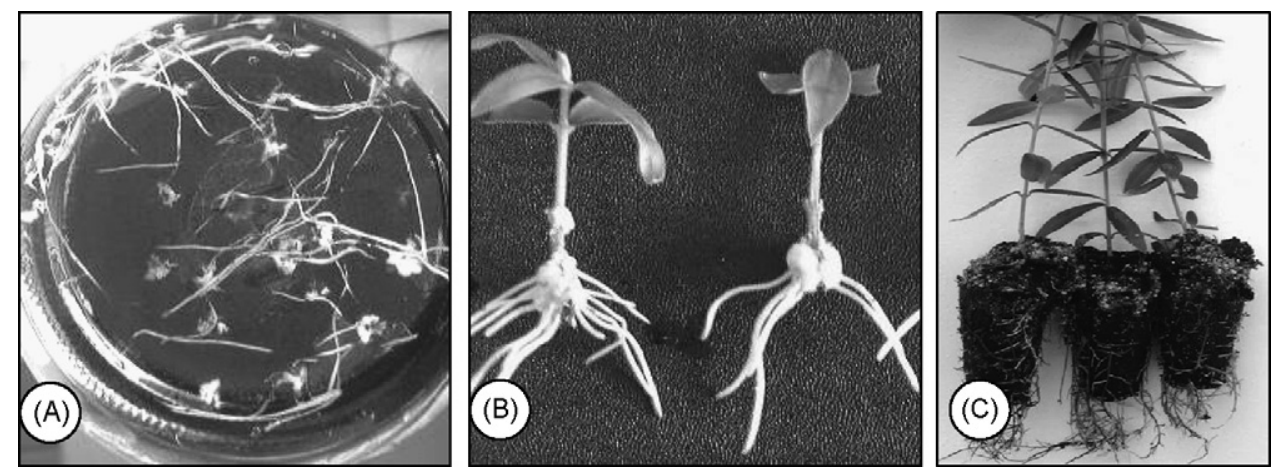

Fig. 6. (A) Between 20 and 30 days after explants transfer into rooting media, the bottom of the culture vessels is filled with new roots. (B) Quality of the plants at the end of the rotting stage. Attention should be given to the number and lengthy of the new roots. (C) New plants 90 days after a successful acclimatization. 
were also carried-out. In the trials, rooting rates over $85 \%$ were achieved using the pulse technique and the supplementation of culture media with activated charcoal. The successful use of the pulse technique was previously reported by Bartolini et al. (1990) and the importance of medium darkening was first evaluated by Rugini et al. (1988) and recently reported by Mencuccini (2003). On this subject Canas et al. (1992) reported that the use of activated charcoal for culture medium darkening did not provide further advantages in olive taking into account that it absorbs the growth regulators in culture medium, making its use difficult by the cultured explants. However, in the trials here presented, activated charcoal was successfully used in the rooting process and, probably due to the rooting medium not having growth regulators in its formulation, no evidence of the constraints described above were observed.

The in vitro rooted plants presented four to six strong new roots and showed excellent plant acclimatization results, with $95 \%$ of plant survival. Acclimatization was achieved by direct placement of the plants under mist on a traditional rooting bench, as used for semi-hardwood cuttings, a simple procedure already proposed by Roussos and Pontikis (2002) that highly simplified the acclimatization process.

\section{Conclusions}

A full protocol for micropropagation of the Portuguese olive cultivar 'Galega vulgar' was presented. The data revealed multiplication and rooting rates compatible for the mass propagation of the cultivar, with one in vitro rooted plant being produced in two and a half to three and a half months. Using significantly lower-price compounds to replace zeatin on all the micropropagation stages, the major objectives of the trials were achieved. The only concern with the use of coconut water in commercial micropropagation protocols is the stability of the zeatin concentration in its composition. During the 2-year experimental period that Sigma ${ }^{\circledR}$ deproteinized and filtersterilized coconut water was used, different lots were tested and the results always presented a very high regularity. Nevertheless, to significantly reduce media fees, coconut water from commercial presentations or directly taken from fresh coconuts should be tested in future trials. The use of the pulse technique for in vitro rooting, associated to a culture media without growth regulators, allows also avoiding one replication during the in vitro rooting process, procedure usually necessary when these compounds are directly added to the rooting media. The good results obtained with the use of traditional water-cooling and mist-bench equipped greenhouses for plant acclimatization highly simplifies the transplanting process, and will be of economical importance for the traditional olive nurseries interested in investing in micropropagation facilities. The protocol here presented is now being tested on other economically important olive cultivars.

\section{Acknowledgements}

The authors wish to thank Francisco Lúcio Santos, Renato Coelho, and Birgit Arnholdt-Schmitt for the reviewing of the manuscript and for the pertinent suggestions to improve it. For the Agência de Inovação (RT\&D project ICP-ME_Progalega) and the INIAP (RT\&D project AGRO 683) also a special acknowledgement for the financial support of the research.

\section{References}

Bartolini, G., Leva, A.R., Benelli, A., 1990. Advances on in vitro culture of the olive propagation of cv. Maurino. Acta Hort. 286, 41-44.

Briccoli, C., Godino, G., Nuzzo, V., 2002. Preliminary agronomic evaluation of two cultivars of olive trees obtained from micropropagation methods. Acta Hort. 586, 870-876.

Briccoli-Bati, C., Fodale, A., Mule, R., Trombino, T., 1999. Trials to increase in vitro rooting of Olea europaea L. cuttings. Acta Hort. 474, 91-94.

Canas, L.A., Avila, J., Vicente, M., Benbadis, A., 1992. Micropropagation of olive (Olea europea L.). In: Bajaj, Y.P.S. (Ed.), Biotechnology in Agriculture and Forestry.Springer, Heidelberg, pp. 493-505.

Dimassi, K., 1999. Micropropagation studies of the cv. Kalamon olives (Olea europaea L.). Acta Hort. 474, 83-86.

Dimassi-Theriou, K., 1994. In vitro propagation of cv. Kalamon olives (Olea europaea sativa L.). Adv. Hort. 8, 185-189.

Fiorino, P., Leva, A.R., 1986. Investigations on the micropropagation of the olive (Olea europaea L.). Influence of some mineral elements on the proliferation and rooting of explants. Olea 17, 101-104.

García, J.L., Troncoso, J., Sarmiento, R., Troncoso, A., 2002. Influence of carbon source and concentration on the in vitro development of olive zygotic embryos and explants raised from them. Plant Cell Tissue Org. Cult. 69, 95-100.

García-Férriz, L., Ghorbel, R., Ybarra, M., Marì, A., Belaj, A., Trujillo, I., 2002. Micropropagation from adult olive trees. Acta Hort. 586, 879-882.

Grigoriadou, K., Vasilakakis, M., Eleftheriou, E.P., 2002. In vitro propagation of the Greek olive cultivar 'Chondrolia Chalkidikis'. Plant Cell Tissue Org. Cult. 71, 47-54.

Hall, R.M., Drew, R.A., Higgins, C.M., Dietzgen, R.G., 2000. Efficient organogenesis of an Australian passionfruit hybrid (Passiflora edulis $\times$ Passiflora edulis var. flavicarpa) suitable for gene delivery. Aust. J. Bot. 48 (5), 673-768.

Ismail, S., Naqvi, B., Anwar, N., Zuberi, R., 2003. In vitro multiplication of Coffea arabica. Pak. J. Bot. 35 (5), 829-834.

Leva, A.R., Petruccelli, R., Goretti, R., Panicucci, M., 1992. Ruolo di alcuni microelementi e carboidrati nella proliferazione 'in vitro' di cv. di olivo (Olea europaea L.). Atti Conv. "Olive oil quality" Firenze 1992, 333-334.

Leva, A.R., Petruccelli, R., Bartolini, G., 1994. Mannitol in vitro culture of Olea europaea L. (cv. Maurino). Acta Hort. 356, 43-46.

Mencuccini, M., 2003. Effect of medium darkening on in vitro rooting capability and rooting seasonality of olive (Olea europaea L.) cultivars. Sci. Hort. 97, 129-139.

Mencuccini, M., Micheli, M., Standardi, A., 1997. Micropropagazione dell'olivo: effetto di alcune citochinine sulla proliferazione. Italus Hortus 4 (6), 32-37.

Murashige, T., Skoog, F., 1962. A revised medium for rapid growth and bioassays with tobacco tissue culture. Physiol. Plant. 15, 473-497.

Rama, P., Pontikis, C., 1991. In vitro propagation of olive (Olea europaea L.). J. Hort. Sci. 65 (3), 347-353.

Roussos, P.A., Pontikis, C.A., 2002. In vitro propagation of olive (Olea europaea L.) cv. Koroneiki. Plant Growth Regulat. 37, 295-304.

Rugini, E., 1984. In vitro propagation of some olive (Olea europaea sativa L.) cultivars with different root-ability, and medium development using analytical data from developing shoots and embryos. Sci. Hort. 24, 123-134.

Rugini, E., Bazzoffia, A., Jacoboni, A., 1988. A simple in vitro method to avoid the initial dark period and to increase rooting in fruit trees. Acta Hort. 227, 438-440.

Rugini, E., Jacoboni, A., Luppino, M., 1993. Role of basal darkening and exogenous putrescine treatment on in vitro rooting and on endogenous polyamine changes in difficult-to-root woody species. Sci. Hort. 53, 6372. 
Rugini, E., Gutierrez-Pesce, P., Sampinato, P.L., 1999. New perspective for biotechnologies in olive breeding: morphogenesis, in vitro selection and gene transformation. Acta Hort. 474, 107-110.

Santos-Hernandez, L., Martinez-Garcia, M., Campos, J.E., Aguirre-Leon, E., 2005. In vitro propagation of Laelia albida (Orchidaceae) for conservation and ornamental purposes in Mexico. HortScience 40 (2), 439-442.
Sghir, S., Chatelet, Ph., Ouazzani, N., Dosba, F., Belkoura, I., 2005. Micropropagation of eight Moroccan and French olive cultivars. HortScience 40 (1), 193-196.

Zuccherelli, G., Zuccherelli, S., 2002. In vitro propagation of 50 olive cultivars. Acta Hort. 586, 931-934. 